NBER WORKING PAPER SERIES

INVENTORIES AND THE

PROPAGATION OF SECTORAL SHOCKS

Russell Cooper

John Haltiwanger

Working Paper No. 2425

NATIONAL BUREAU OF ECONOMIC RESEARCH

1050 Massachusetts Avenue

Cambridge, MA 02138

November 1987

Helpful suggestions and comments from participants at the 1987 NBER Summer Institute Meetings are greatly appreciated. Financial support from the Lynde and Harry Bradley Foundation, from the National Science Foundation for Cooper, through SES 8605302 and a grant to the Hoover Institution's National Fellows Program, and for Haltiwanger, through SES 8520697, is gratefully acknowledged. The research reported here is part of the NBER's research program in Economic Fluctuations. Any opinions expressed are those of the authors and not those of the National Bureau of Economic Research. 


\title{
Inventories and the Propagation of Sectoral Shocks
}

\begin{abstract}
This paper studies the dynamic properties of an imperfectly competitive economy with inventory holdings. In particular, we focus on the serial correlation in aggregate output and employment produced by the holding of inventories in one sector of the economy and the co-movement between sectors of an economy over the cycle resulting from demand linkages. This model is then contrasted with a simple, competitive real business cycle model with inventories. We find that the predictions of these models with regards to the co-movement of employment may differ. Based on this, we present empirical evidence on the co-movement of employment over the business cycle which is consistent with the predictions of the model of imperfect competition with inventory holdings and demand linkages.
\end{abstract}

Russell Cooper

Hoover Institution, HHMB

Stanford University

Stanford, California

$94305-2323$
John Haltiwanger

Department of Economics University of Maryland College Park, Maryland 20742 
Inventories and the Propagation of Sectoral Shocks

\section{Introduction}

Macroeconomists are generally concerned with characterizing the positive and normative aspects of business cycles. Two important features of cycles are: (i) correlated movements in aggregate output over time and (ii) the positive co-movement in output and employment between sectors over the cycle. Discussions of these observations appear, for example, in Lucas [1977], LongPlosser [1983], Zarnowitz [1985]. ${ }^{1}$ For the purpose of building models of the cycle, the task is to determine the features of preferences, endowments, technology and information, along with the institutional structure in which agents interact, that reproduce these two key observations.

Macroeconomic theorists (see, for example, Kydland-Prescott [1982]) have focused on correlated movements in output over time by studying the wide variety of intertemporal linkages (capital, non-separable preferences, stochastic structure) present in the economy. This emphasis on persistence reflects both the extensive use of the representative agent paradigm and the fundamental concern of macroeconomists over aggregate quantities. This literature highlights both possible sources of aggregate fluctuations (monetary shocks, real shocks, etc.) as well as the mechanisms which propagate these disturbances throughout the economic system.

Formulating models to understand the co-movement in employment and output across sectors is a bit more difficult. To see why, consider an extreme economy in which workers suffer no disutility from work so that equilibrium is always at full employment. Then, variations in output and employment in one sector, say due to sector specific technology shocks, will cause opposite movements in other sectors. That is, sectoral shocks may produce the 
substitution of resources from one sector to another rather than the positive co-movement observed in practice. While these substitution effects dominate in this extreme case, they are certainly present in other, less-extreme, settings as well. ${ }^{2}$

One means of producing positive co-movement in employment and output is through economy-wide rather than sectoral shocks. Lucas [1972,1975] accomplishes this in an economy subject to aggregate monetary disturbances which individual agents confuse with real shocks. As an alternative to monetary disturbances, aggregate real disturbances could be the source of aggregate fluctuations in employment and output. An increase in economy-wide productivity would generally increase output in all sectors of the economy. However, the effect on employment may be ambiguous due to offsetting income and substitution effects.

Long-Plosser [1983] present a model in which aggregate fluctuations in output arise from sector specific rather than aggregate technology shocks. This emphasis on sectoral shocks is perhaps more convincing since it is difficult to identify aggregate supply disturbances associated with each turn of the business cycle. In the Long-Plosser model economy, a technology shock in one sector leads to a contemporaneous expansion in that sector's output. This additional output is partly consumed and partly used as an input in the production of other commodities for next period. The resulting output of the other commodities is then partly consumed and partly used as additional inputs, etc. In this manner shocks to the production function in a single sector are spread over time and to other sectors creating persistent aggregate fluctuations. In the extensive example of Long-Plosser, equilibrium employment is constant as income and substitution effects are offsetting. Thus as stated, their example fails to match the observed co-movement in 
sectoral employment levels over the cycle. We return to this point later.

This paper provides an alternative framework for understanding the comovement in output and employment in a multi-sector setting. In contrast to Long-Plosser's emphasis on technological linkages and factor demand flows, our approach highlights demands for final consumption goods as the important linkage between sectors and excludes production of commodities by commodities. Instead, the intertemporal linkage in the model is the holding of inventories by the firm in one sector and the linkage across sectors is through demands for final goods only. Further, we are interested in generating empirical implications for the co-movement in employment levels across sectors over the cycle.

The normality of demands for consumption goods is the basis for the propagation of shocks from one sector to another. These demand linkages create output and employment movements rather than price changes when the economy is in an underemployment equilibrium in which all available resources are not fully utilized. The source of the underemployment is imperfect competition. Hart [1982], Weitzman [1985], Cooper [1986] and Hall [1987a] also emphasize the importance of imperfect competition in generating large quantity fluctuations relative to perfect competition because the economy is more likely to be in an underemployment region when sellers of goods and/or labor have market power. ${ }^{3}$

One important feature of our paradigm is that only one sector can hold inventories. This reflects the fact that many sectors of the economy produce goods and services which cannot be held in inventory. However, as a consequence of the demand linkages across sectors, the holdings of inventories in a subset of the sectors is sufficient to produce persistence in the output of all sectors. A buildup of inventories in one sector will reduce production 
in that sector which then leads to a reduction in demand for the product of other sectors. In the underemployment equilibrium this decrease in demand is met by reductions in output and employment. Section II presents a version of this model in which imperfect competition is a key feature of the environment and validates these claims about persistence and co-movement.

To further facilitate a comparison of approaches, Section III presents a simple, competitive real business cycle model with inventory holdings in one sector. Absent mobility costs, shocks to this system will produce negatively correlated movements in output and employment as workers shift from one sector to another. As one sector expands, the other tends to contract.

Section IV reconciles these results with the model of imperfect competition. The point of this discussion is to identify the key assumptions which determine whether employment movements are positively or negatively correlated across sectors. The main conclusion of the analysis then is that perfectly competitive economies tend to produce more substitution between activities than imperfectly competitive economies.

Drawing on this implication, Section $V$ of the paper looks at the evidence on employment fluctuations over time and across sectors. Our main finding is that employment fluctuations are generally positively correlated across sectors at the frequency of monthly data. We argue that this provides support for the underemployment equilibrium model relative to a real business cycle model in which shocks induce the reallocation of workers across sectors.

\section{Imperfect Competition, Propagation and Inventories}

To study these issues, consider a two period imperfectly competitive economy. There are two goods produced by monopolists and a third, nonproduced good, endowed to a group of agents termed outsiders. There are also 
$2 \mathrm{~N}$ workers present each period who sell their labor services to firms.

The monopolist in each of the two sectors produces a unit of output from each unit of labor. In making production decisions, firms recognize their market power as sellers. These agents consume the non-produced good in each period and, as buyers, act as price takers. Their preferences (formally those of their shareholders) are given by $V\left(m_{t}\right)$ in each period where $v()$ is increasing and concave and $\mathrm{m}_{\mathrm{t}}$ is their consumption of the nonproduced good in period $t$. To produce, these firms hire workers in a competitive labor market. ${ }^{4}$

The sectors differ in two important respects. First, in period 1 the monopolist in sector 1 receives an endowment of that good, $e_{1}$. Second, this agent can hold goods over time as inventories. The sector 2 monopolist has a zero endowment and is unable to hold inventories. This specification permits us to analyze the interaction between sectors holding inventories (such as manufacturing) and those for which inventory holding is impossible (services).

There are two types of outsiders. Type $i$ outsiders have an aggregate endowment of $\bar{M}^{i}$ units of the non-produced good in each of the two periods. They demand both the non-produced good and the good produced in sector $i$ and have homothetic preferences. Their demands for sector $i$ output and the nonproduced good are given by

$$
\mathrm{q}_{i}=\mathrm{h}\left(\mathrm{p}_{\mathrm{i}}\right) \overline{\mathrm{M}}^{\mathrm{i}} \quad \text { and } \quad \mathrm{m}=\overline{\mathrm{M}}^{\mathrm{i}}\left(1-\mathrm{p}_{\mathrm{i}} \mathrm{h}\left(\mathrm{p}_{\mathrm{i}}\right)\right)
$$

With homothetic preferences, demands are proportional to income so that variations in $\bar{M}^{i}$ induce proportional variations in the demand for the produced good. The function $\mathrm{h}()$ is decreasing and, since demands are positive, $1>$ $\mathrm{ph}(\mathrm{p})$ for $\mathrm{p}>0.5$

There are $2 \mathrm{~N}$ workers born each period who are endowed with a unit of 
leisure. Workers are of two possible types depending on the location of their employment. Those employed in sector $i$ consume the nonproduced good and the good produced in the other sector (denoted hereafter by $-i$ ). This is a common preference structure for these models (see, for example, Cooper-John [1987] or Heller [1986]) as it highlights the fact that agents generally consume goods other than those which they produce.

For simplicity, workers in sector $i$, who consume good $-i$, have the same preferences as type $-i$ outsiders. Workers employed in sector $-i$ receive a wage of $w$ and demand $h\left(p_{i}\right) w$ units of good $i$. Their indirect utility function is given by $\mathrm{Z}\left(\mathrm{w}, \mathrm{p}_{\mathrm{i}}\right) \equiv \mathrm{U}\left(\mathrm{h}\left(\mathrm{p}_{\mathrm{i}}\right) \mathrm{w},\left(1-\mathrm{h}\left(\mathrm{p}_{\mathrm{i}}\right) \mathrm{p}_{\mathrm{i}}\right) \mathrm{w}\right)-\mathrm{k}$ where $\mathrm{k}>0$ is the disutility of working and $U()$ is increasing, concave and homothetic. $Z \geq 0$ is necessary for worker participation in the market.

Before proceeding it may be fruitful to evaluate the assumptions made thus far. We have restricted attention to two periods and two sectors for ease of presentation. Extensions to more time periods and sectors would not dramatically affect our results.

One important assumption is that there are monopolists in the two sectors. If these markets were oligopolistic, the analysis would be much more difficult as it would require the characterization of a dynamic Cournot-Nash equilibrium with inventories. In this setting, inventories would play an important strategic role as discussed by Arvan [1985] and Rotemberg- Saloner [1987]. While this is an interesting possibility, it did not seem crucial to our line of inquiry and is avoided by the monopolistic setting.

Finally, the structure of demands here is quite important. The monopolists are assumed to consume only the non-produced good while the workers consume the produced goods. This implies that the current spending of workers is the key linkage across the sectors of the economy and firms' profits represent a 
leakage from the expenditure stream. This is similar to the structure imposed by Hart [1982] in his discussion of the importance of income distribution in models of imperfect competition.

One way to think about this is to view consumption of the non-produced good, in part, as a proxy for future consumption in an infinite horizon setting. In that environment, our (implicit) assumption is that firms (i.e. their owners) have a higher marginal propensity to save than workers. This could be explicitly modeled by assuming that workers live many periods but face credit constraints that limit their participation in capital markets thus increasing their marginal propensity to consume. Firms, on the other hand, have the ability to borrow and lend. With this approach, workers would be viewed as "Keynesian consumers" while firms are "life cycle consumers". 6 Instead of formally analyzing these capital market imperfections and working with the infinite horizon model, we simply assume that workers have a shorter time horizon than firms and that only workers engage in consumption of the produced good each period.

To characterize the equilibrium for this two period model, we first consider the equilibrium in period 2 taking as given the inventory holdings of the sector 1 monopolist. We then consider the first period choice problems and the overall equilibrium.

Period 2 analysis for given Inventories

In period 2, the sector 1 firm has inventories from the previous period which we denote by $I_{1} \geq 0$ This monopolist is interested in maximizing income, in terms of its consumption good (the non-produced good), and solves

(2) $\underset{q_{2}^{1}}{\operatorname{maximize}} \mathrm{p}\left(\mathrm{q}_{2}^{1}+\mathrm{I}_{1}\right)\left(\mathrm{q}_{2}^{1}+\mathrm{I}_{1}\right)-\mathrm{w}_{2} \mathrm{q}_{2}^{1}$. 
Throughout this presentation, superscripts index the sector and subscripts index the time period. The demand for sector 1 output comes from the outsiders and sector 2 workers and is

$$
\mathrm{q}_{2}^{1}+\mathrm{I}_{1}=\mathrm{h}\left(\mathrm{p}_{2}^{1}\right)\left(\overline{\mathrm{M}}^{1}+\mathrm{q}_{2}^{2} \mathrm{w}_{2}\right)
$$

The inverse demand curve in (2), comes directly from (3). Using (3), the solution to the monopolist's problem is

(4) $\mathrm{p}_{2}^{1}\left[1+\xi\left(\mathrm{p}_{2}^{1}\right)\right]=\mathrm{w}_{2}$.

where $\xi(\mathrm{p}) \equiv \frac{\mathrm{h}(\mathrm{p})}{\mathrm{ph}^{\prime}()}<0$ is the inverse of the price elasticity of demand.

Because of the homothetic preferences and constant marginal costs, the mark-up of prices over marginal cost (the wage rate) is independent of the level of output. Thus variations in output and/or inventory holdings will only influence prices when wages are sensitive to employment levels.

The maximization problem of the monopolist in sector 2 is identical to that of the sector 1 monopolist with the restriction that $I_{1}=0$ since there are no inventories in sector 2. The demand for sector 2 output is given by (3) with the appropriate changes in the income level of the consumers of good 2 . The solution to the monopolist's optimization problem is therefore

(5) $\mathrm{p}_{2}^{2}\left[1+\xi\left(\mathrm{p}_{2}^{2}\right)\right]=\mathrm{w}_{2}$.

Equations (4) and (5) link the prices in the two sectors to the wage rate in period 2 through $\xi()$. Since both firms hire workers at the same wage and face 
demand curves with the same elasticities, the prices in the two sectors will be equal. ${ }^{7}$ Denote by $\mathrm{p}_{2}$ this common price for period 2 .

Inserting $\left(\mathrm{w}_{2}, \mathrm{P}_{2}\right)$ into the sector demand curves yields. two equations describing the of output for each of the two sectors at these prices. These are given by

(6) $\mathrm{q}_{2}^{1}=\mathrm{h}\left(\mathrm{p}_{2}\right)\left(\overline{\mathrm{M}}^{1}+\mathrm{w}_{2} \mathrm{q}_{2}^{2}\right)-\mathrm{I}_{1}$ for sector 1 and

(7) $q_{2}^{2}=h\left(p_{2}\right)\left(\bar{M}^{2}+w_{2} q_{2}^{1}\right)$ for sector 2 .

For convenience of exposition, (6) is a restatement of (3). Note that the demand for sector 2 output depends on the level of output not sales in sector 1. This is because the linkage between sectors is through the demands of workers not firms. Hence, a decrease in sector 1 production, perhaps due to an increase in the inventories held by sector 1 firms, will reduce the demand for sector 2 output.

Figure 1 provides a graphical representation of these two curves. Their intersection determines the levels of output for the two sectors for given $\left(w_{2}, P_{2}\right)$. For $I_{1}$ small, both curves have a positive intercept term and slopes less than one, since $\mathrm{p}_{2}>\mathrm{w}_{2}$ from (5) and $\mathrm{ph}(\mathrm{p})<1$. As the inventory holdings of sector 1 firms increase, the level of production in that sector will fall at each level of sector 2 output given $\left(\mathrm{w}_{2}, \mathrm{p}_{2}\right)$. Since we will ultimately characterize an equilibrium in which wages and prices will not vary with $I_{1}$, these comparative statics will be important in understanding the linkage between period 1 inventory holdings and the period 2 equilibrium levels of output and employment.

\section{Period 1 Choice Problems and Equilibrium}




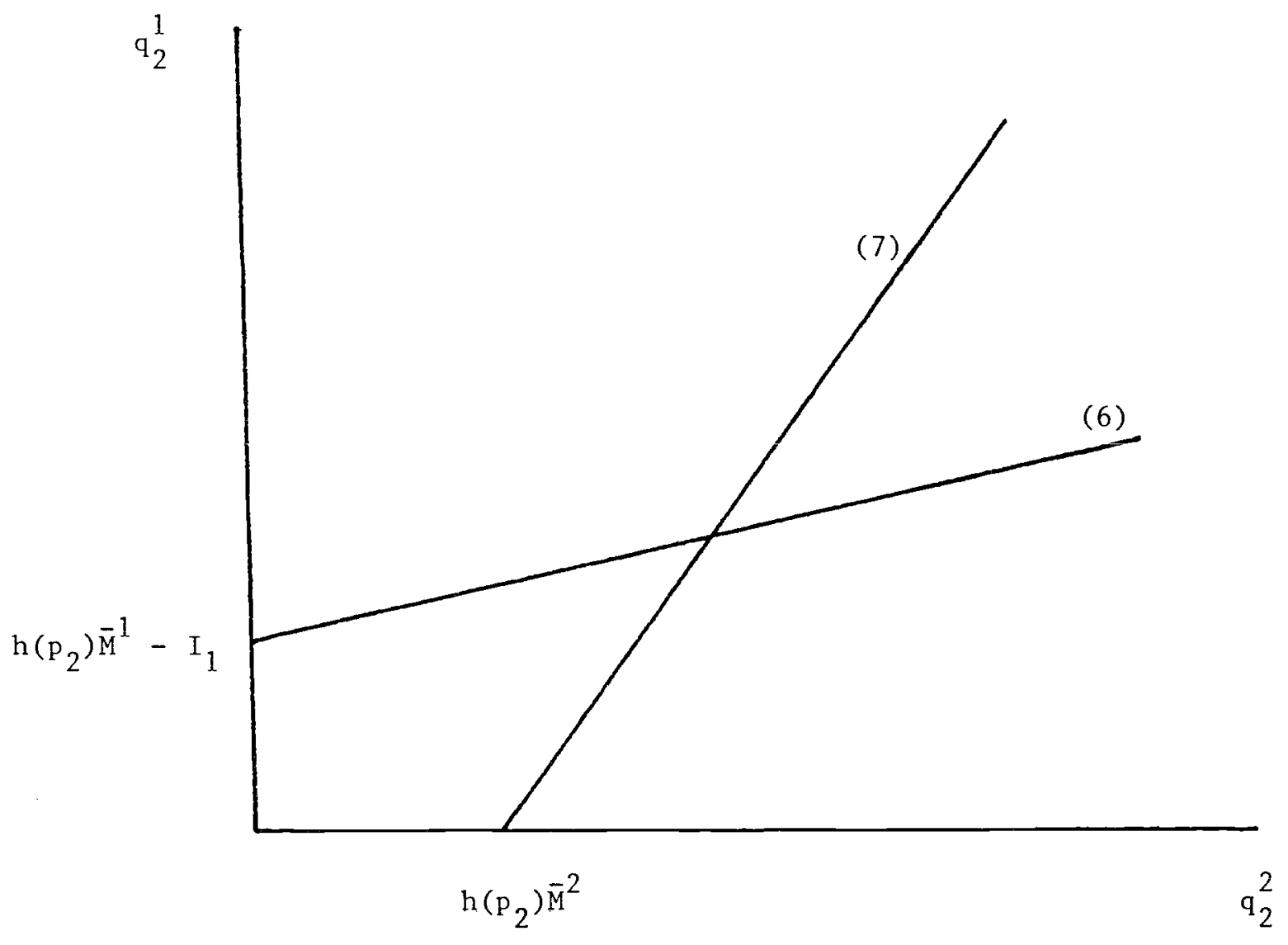

FIGURE 1 
The period 1 choice problem of the monopolist in sector 2 , the workers and the outsiders are exactly the same as their period 2 choice problems since none of these agents solve intertemporal problems. In particular, the sector 2 monopolist's first order condition is given by

$$
\mathrm{p}_{1}^{2}\left[1+\xi\left(\mathrm{p}_{1}^{2}\right)\right]=\mathrm{w}_{1}
$$

This is identical to (5) except for the change in the decision period.

The sector 1 monopolist selects an output level and inventory holdings to

$$
\text { (10) } \max V\left(\pi_{1}^{1}\right)+V\left(\pi_{2}^{1}\right)
$$

where

$$
\begin{aligned}
& \pi_{1}^{1}=\left(\mathrm{q}_{1}^{1}+\mathrm{e}_{1}-\mathrm{I}_{1}\right) \mathrm{p}_{1}^{1}()-\mathrm{w}_{1} \mathrm{q}_{1}^{1} \text { and } \\
& \pi_{2}^{1}=\left(\mathrm{q}_{2}^{1}+\mathrm{I}_{1}\right) \mathrm{p}_{2}^{1}()-\mathrm{w}_{2} \mathrm{q}_{2}^{1} .
\end{aligned}
$$

Here $w_{2}$ is the period 2 equilibrium wage anticipated by this firm. The period 2 price function, $\mathrm{p}_{2}^{1}()$ is the inverse demand function that the firm conjectures for the next period. In equilibrium, these conjectures will be correct. In the expression for period 1 profits, $e_{1}$ is the monopolist's endowment in the first period. The first order conditions for this problem are

(11) $\quad V^{\prime}\left(\pi_{2}^{1}\right) M R_{2}^{1}=V^{\prime}\left(\pi_{1}^{1}\right) M_{1}^{1}$ and

(12) $\mathrm{p}_{1}^{1}\left[1+\xi\left(\mathrm{p}_{1}^{1}\right)\right]=\mathrm{w}_{1}$.

In (11), $\mathrm{MR}_{\mathrm{t}}^{1}$ refers to the marginal revenue of selling an extra unit of sector 1 output in period $t=1,2$. Expression (12) is analogous to (4) and implies that within period 1 marginal revenue will equal marginal cost. Using (12) 
and (4), (11) can be rewritten as

(13) $V^{\prime}\left(\pi_{1}^{1}\right) \mathrm{w}_{1}=V^{\prime}\left(\pi_{2}^{1}\right) \mathrm{w}_{2}$

Expression (13) characterizes the intertemporal decision of the monopolist. The gain to holding more inventories from period 1 to 2 is given by the right side of (13). The monopolist saves the labor cost associated with producing an extra unit times the marginal utility of period 2 income. The cost of holding inventories is the wage for hiring the extra worker times the marginal utility of period 1 income. In this economy, as in the Blinder-Fischer [1981] yeoman farmer model, inventories are used to smooth consumption.

At these wages and prices, the quantities produced in the two sectors are given by expressions analogous to (6) and (7). These are

(14) $\mathrm{q}_{1}^{1}=\mathrm{h}\left(\mathrm{p}_{1}\right)\left(\overline{\mathrm{M}}^{1}+\mathrm{w}_{1} \mathrm{q}_{1}^{2}\right)+\mathrm{I}_{1}-\mathrm{e}_{1} \quad$ and

(15) $\mathrm{q}_{1}^{2}=\mathrm{h}\left(\mathrm{p}_{1}\right)\left(\overline{\mathrm{M}}^{2}+\mathrm{w}_{1} \mathrm{q}_{1}^{1}\right)$.

Figure 2 provides a graphical representation of these two equations for a given value of $\left(I_{1}-e_{1}\right)$.

\section{Equilibrium}

Our interest is in the behavior of the economy in a stationary underemployment equilibrium where total employment and output is the same each period and is strictly less than $2 \mathrm{~N}$. To do so, assume that $\mathrm{e}_{1}=0$ and that $\overline{\mathrm{M}}^{\mathrm{i}}=\overline{\mathrm{M}}$ in each period so that preferences, endowments and technology are all stationary and the sectors are symmetric. Given the symmetry between the sectors of the economy, the equilibrium wages are independent of time and the equilibrium prices are independent of time and sector. We denote these by $\left(w^{*}, p^{*}\right)$. 


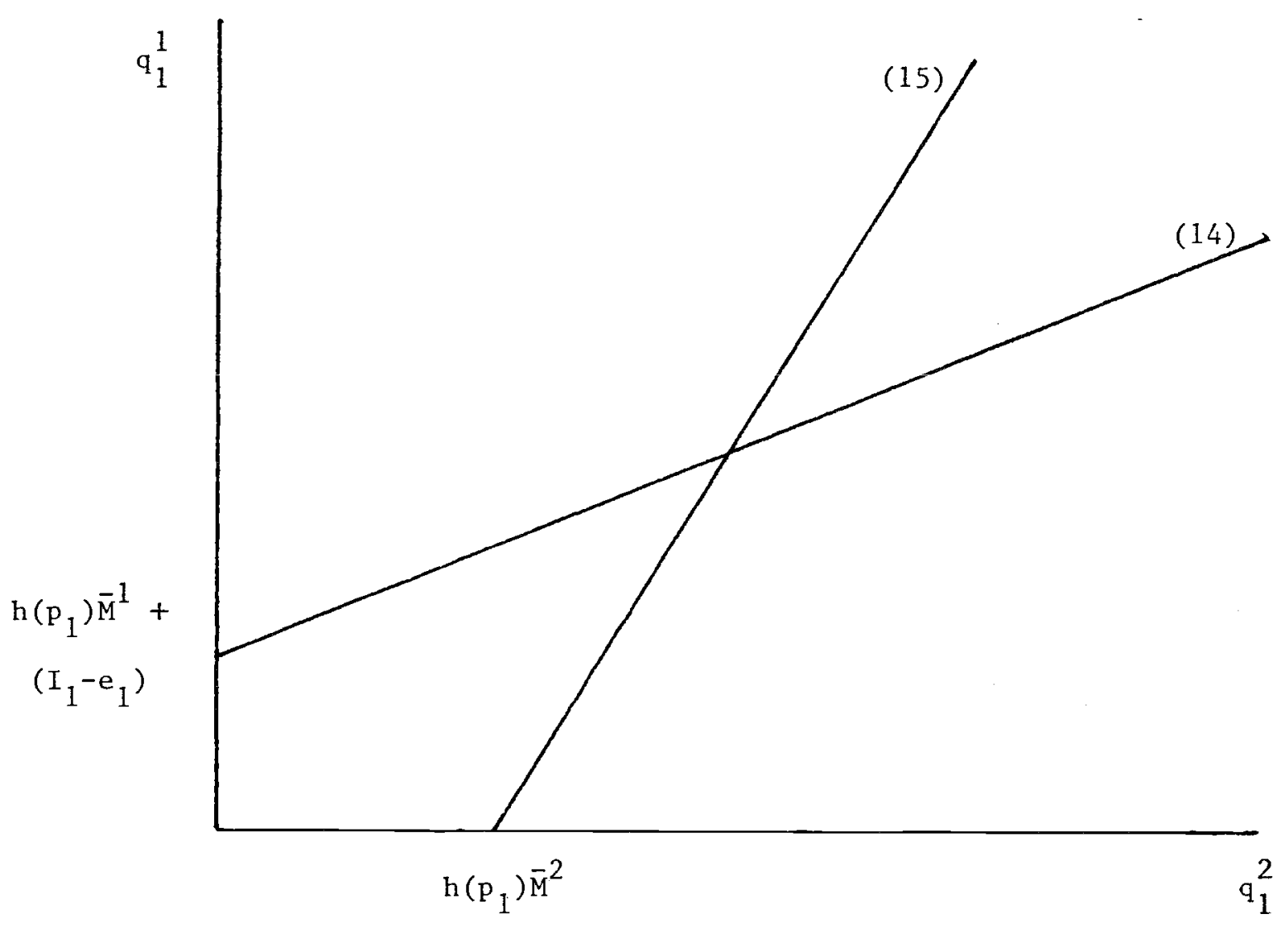

FIGURE 2 
In an underemployment equilibrium, workers will be indifferent between working and not. Hence the participation constraint

$$
\mathrm{Z}\left(\mathrm{w}^{*}, \mathrm{p}^{*}\right)=0
$$

will be binding.

To characterize an underemployment equilibrium, solve for the ( $\left.w^{*}, \mathrm{p}^{*}\right)$ that simultaneously solves (16) and one of the identical mark-up equations, say (4). This is an equilibrium if the outputs demanded at these prices are producible given the technology and number of workers in the economy; i.e. labor markets clear when (16) holds. Given the stationarity and symmetry, this condition must hold in both sectors and time periods and is:

$$
q^{*}=h\left(p^{*}\right)\left[\bar{M}+w^{*} q^{*}\right]<N
$$

Proposition 1: If $\bar{M}$ is not too large relative to $N, e_{1}=0$ and $\bar{M}^{i}=\bar{M}$ for $i=1,2$, then there will exist a symmetric, stationary underemployment equilibrium for this economy with prices and wages determined by (4) and (16) and quantities determined by demand at these prices.

Proof: See Appendix.

Figure 3 depicts an equilibrium (w,p) from the crossing of a worker's indifference curve (16) with one of the mark-up equations, (4). Note that multiple equilibria are possible if $\xi(p)$ varies enough to create multiple crossings of these curves. This possibility is discussed in Heller [1986]. Uniqueness of equilibrium is guaranteed by assuming a constant elasticity specification.

If the conditions for Proposition 1 do not hold, then the economy could be in a full employment equilibrium. In that case, the behavior of the economy in response to shocks is radically different than in the underemployment 


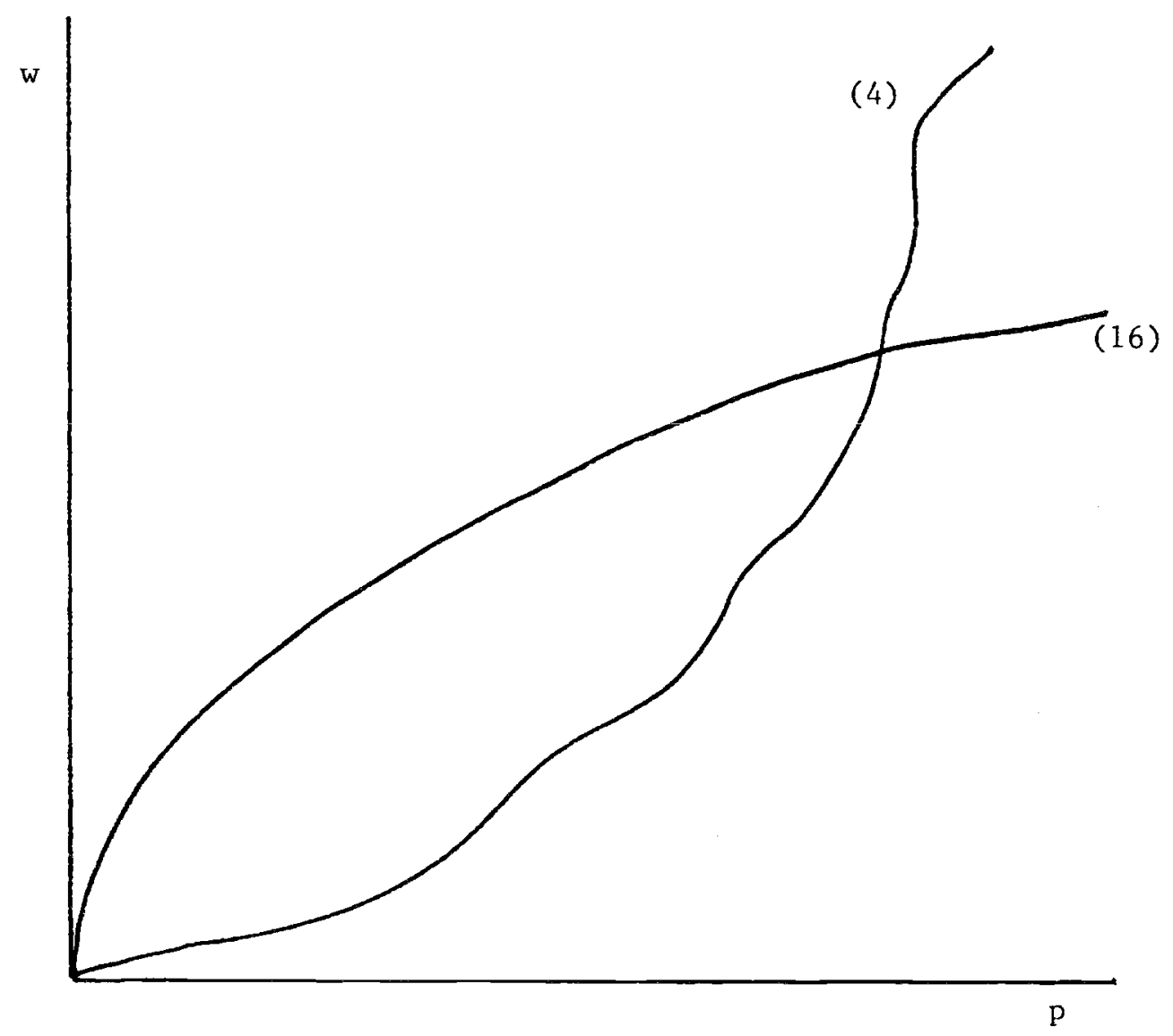

FIGURE 3 
regime. We emphasize the latter case in the analysis to follow and then return to a discussion of the full employment economy in Section IV of the paper.

Effects of changes in period 1 endowment

Consider the effect on the economy of an increase in the endowment of the monopolist in period 1 at a stationary, underemployment equilibrium. ${ }^{8}$ This exercise of varying an endowment is similar to that outlined by BlinderFischer [1981] as a vehicle for understanding the propagation effects of holding inventories. There are a number of alternative shocks that could be considered in this framework such as fluctuations in marginal products and/or variations in the endowment levels of the outsiders. While this might be of independent interest, for the purpose of focusing on the propagation effects of inventories on future production, consumption and employment, the analysis under either of these two alternatives would be the same as that conducted here.

An increase in $e_{1}$ has two important effects. From (14), the output of the sector 1 monopolist would fall for given inventory holdings. So, in Figure 2, this causes a shift down in the line expressing sector 1 output as a function of sector 2 output in period $1 .{ }^{9}$ As seen from this figure, this causes a reduction in sector 2 output as well. However, from (13), part of this increase in endowment would be held as inventories by the monopolist. From (6), this increased level of inventories will then reduce the sector 1 monopolist's output in period 2. This reduction in sector 1 output in the two periods spills over to sector 2 because sector 1 employment falls. A decrease in sector 1 employment reduces demand for sector 2 output since the linkage across the sectors is based on the demands of the workers. This is seen in Figure 1 as a shift down in the line expressing sector 1 output as a function 
of sector 2 output in period 2. These effects are summarized by

Proposition 2: An increase in $e_{1}$ will increase $I_{1}$ and reduce $q_{t}^{i}$ for $i=1,2$ and $t=1,2$.

Proof: From (11), if an increase in $e_{1}$ increases $\pi_{1}^{1}$, then $I_{1}$ must increase so that this condition is met. However, the increase in $I_{1}$ will not exceed the increase in $e_{1}$. Holding inventories constant and using (12), an increase in $e_{1}$ increases $\pi_{1}^{1}$ by $\mathrm{MR}_{1}^{1}$. So, in order for (11) to hold, $I_{1}$ must increase with $e_{1}$ but by less than $e_{1}$.

From (14), this implies that period 1 output for sector 1 will fall and from (6) period 2 output will fall as well. Since sector 2 output is an increasing function of sector 1 output (not sales) in both periods, sector 2 output will fall as well.

QED.

The key to this result is the positive interaction across sectors in the economy. Reduction in sector 1 output in each of the periods is a consequence of a positive endowment shock and the smoothing behavior of inventory holdings as the monopolist seeks to spread the endowment increase over time. The resulting reduction in sector 1 output spreads to sector 2 through the reduced demands of the unemployment workers. Thus these demand spillover effects, coupled with the persistence created by the holding of inventories, generates correlated movements in output and employment across sectors and over time.

In the following section, this result is contrasted with that of a simple real business cycle model. It is also useful to contrast Proposition 2 with an alternative model of coordination failures stemming from the search behavior of consumers/producers. One such model is that of Diamond [1982] in which agents decide whether or not to accept production opportunities given that they must meet a trading partner in order to consume. In this setting, 
increased inventory holdings by other agents may create incentives for prospective partners to accept more production opportunities since the likelihood of meeting a trading partner increases when inventory holdings are higher. Thus instead of reducing production in other sectors, higher inventories actually encourage production.

\section{A Real Business Cycle Model with Sectoral Reallocation}

The objective of this section is to construct a real business cycle model with inventory holdings and to contrast its implications with the results from Section II. The model differs from that in Section II both in terms of the market structure and in the specification of agents' preferences. In particular, we follow the real business cycle literature by assuming that the market allocation corresponds to the solution of a planner's problem and that there is a single agent in the economy. The analysis in this section highlights the role of sector specific shocks in inducing the sectoral reallocation of workers. These differences in assumptions and results are discussed in some detail in Section IV of the paper. This section forms a useful bridge between the economy described in Section II and the Long-Plosser mode1.

Consider a Robinson Crusoe economy in which the single agent has preferences described by:

(18) $\sum_{t=1}^{2} \beta^{t}\left\{U^{1}\left(c_{t}^{1}\right)+U^{2}\left(c_{t}^{2}\right)+U^{3}\left(m_{t}\right)-g\left(n_{t}\right)\right\}, n_{t}=n_{t}^{1}+n_{t}^{2}$.

where $U^{i}()$ is concave, $g()$ is convex and both are twice continuously differentiable. As in the section II model, there are two produced goods $\left(c_{t}^{1}, c_{t}^{2}\right)$ and one non-produced good $\left(m_{t}\right)$ in each period. Robinson Crusoe is 
endowed with $2 \mathrm{~N}$ units of leisure and $\overline{\mathrm{M}}$ units of the non-produced good in each period. The production technology is given by:

$$
q_{t}^{i}=f^{i}\left(n_{t}^{i}\right), \quad i=1,2
$$

where $f^{\prime}>0$ and $f^{\prime \prime}<0$. Good 1 is storable while good 2 is not. At the beginning of period 1, Robinson Crusoe receives an endowment of good $1, e_{1}$. Robinson Crusoe maximizes utility given by (18) subject to the technology given by (19) and the following feasibility constraints:

(21) $\quad c_{t}^{2}=q_{t}^{2} \quad$ and

(22) $\mathrm{m}_{t}=\overline{\mathrm{M}}$.

where $I_{t} \geq 0$ is end-of-period inventories and $I_{0}=e_{1}$. As there is no incentive to hold inventories at the end of period $2, I_{2}=0$. Given this, the optimality conditions (for an interior solution to $n_{t}^{1}, n_{t}^{2}$, and $I_{1}$ ) reduce to:

$$
\begin{aligned}
& U^{i} \cdot\left(c_{t}^{i}\right) f^{i} \cdot\left(n_{t}^{i}\right)=g^{\prime}\left(n_{t}\right) ; \quad i=1,2 ; t=1,2 \\
& U^{1}\left(c_{1}^{1}\right)=\beta U^{1} \cdot\left(c_{2}^{1}\right)
\end{aligned}
$$

Expression (23) implies simply that Robinson Crusoe makes his within period consumption and production decisions so that the marginal utility from the output produced by one additional unit of labor equals the marginal disutility of an additional unit of labor. Expression (24) indicates that inventories are used to smooth the marginal utility of consumption over time.

Now consider the same conceptual experiment conducted in Section II. In particular, consider the effect on the economy of an increase in the endowment 
of good 1 in period 1. As the following proposition demonstrates, in response to an increase in $e_{1}$, Robinson Crusoe will reduce his production in sector 1 and shift resources towards the production in sector 2 in both periods.

Proposition 3: An increase in $e_{1}$ will increase $I_{1}$, decrease $q_{t}^{1}$, and increase $q_{t}^{2}$ for $t=1,2$.

Proof: As long as $e_{1}+q_{1}^{1}$ increases in response to the increase in $e_{1}$, then both $c_{1}^{1}$ and $I_{1}$ must increase in order to satisfy (24). Further, $e_{1}+q_{1}^{1}$ not increasing would violate (23). Observe from (23) that the increased consumption of good 1 in period 1 will induce a reduction in the production of good 1 , which in turn by reducing the marginal disutility of labor induces an increase in the production and hence consumption of good 2. Further, since $\mathrm{I}_{1}$ increases as well this will induce an increase in the consumption of good 1 in period 2. This, in turn, will induce a similar reduction in the production of good 1 in period 2 but an increase in the production of good 2 in period 2.

QED.

Overall, we observe that in this setting the co-movements in inventories, output and employment are very different than those found in the model of Section II. In this environment with complete mobility across sectors and resources necessarily being allocated to their highest value use, inventory movements in one sector induce substitution of resources away from that sector to the other sectors of the economy. Thus neither output nor employment vary together in response to endowment shocks. This contrasts with the co-movement in output and employment present in the specification of Section II. In the subsequent section we discuss what factors underlie the dramatic differences in the predicted behavior of inventories, output and employment across the two alternative specifications. 
Before proceeding, it is useful to bridge the conceptual gap between Propositions 2 and 3 and the results that emerge from the Long-Plosser analysis. Their model differs from ours in two important ways. First, the shock in their model is sector specific productivity disturbance which occurs after the determination of factor inputs. That is, their model contains a stochastic technology with a production lag while we focus on an endowment shock. Second, the use of commodities as inputs in the production of other commodities provides a mechanism for generating positive co-movements in production across sectors and time. In the Long-Plosser model, these linkages are characterized by an input-output matrix with non-zero off-diagonal elements. Our model has a matrix in which the only linkage across commodities and time is the holding of sector 1 inventories.

In contrast to Proposition 3, Long-Plosser demonstrate that their model can produce correlated movements in output across sectors which reflect the inputoutput matrix. As noted earlier, their explicit example yields an allocation in which employment levels in each sector were constant because of the CobbDouglas preferences.

To understand the differences between these models, consider a transitory productivity shock in sector 1 in our model instead of an endowment shock while retaining the assumption of no production lags. The optimality conditions for the planner's problem will equate the marginal disutility of work with the product of the marginal productivity of labor in a given sector and the marginal utility of consuming that sector's output (as in (23)). Suppose that there is a positive productivity shock in sector 1 . If $U\left(c_{t}^{1}\right)$ is not too concave, then employment and output in sector 1 will increase while sector 2 output and employment will decline. ${ }^{10}$ Through inventory holdings, the effects of the productivity shock will be propagated over time. Thus the 
response to a shock to the sector 1 production function would be the substitution of employment across the sectors just as in Proposition 3 so that negative correlations in output and employment across sectors would again be predicted.

To move a step closer to the Long-Plosser specification, suppose that sector 1 output is produced with a lag so that period $t$ output in sector 1 is a function of labor input in period $t-1$ and a shock in period $t$. Further, assume that sector 2 does not have a production lag (i.e. continue to think of that as a service sector). Then, in an infinite horizon version of the model (which is needed to avoid the inconsistency of having a final period in a model with a production lag), a shock to the sector 1 production function in period $t$ will reduce employment in that sector and cause the substitution of labor into sector 2. Output will be higher in both sectors in the period of the shock though sector 1 output will, on average be lower in the next period (assuming i.i.d. shocks) due to the reduction of sector 1 labor input. Note that once again, employment is negatively correlated across sectors as the productivity shock creates substitution effects.

As a final step, suppose that we allow the production of commodities by commodities and assume that labor and other inputs are complements in the production function, as in the Long-Plosser model. A shock to the sector 1 production function will then cause a decline in the marginal utility of consuming sector 1 output. Since some of this additional output is used in the production of sector 1 goods next period, this increases the marginal productivity of labor. Thus, as discussed by Long-Plosser, there is an ambiguity regarding the response of employment to productivity shocks in the Long-Plosser setting. A sufficiently large technological complementarity between inputs and labor in all sectors relative to the curvature of the 
utility function is required to generate positively correlated movements in employment. In a sense, the effect of the technological linkages between sectors in the Long-Plosser model can be similar to an economy-wide technology shock inducing both income and substitution effects and hence an ambiguous effect on employment in each sector. If, however, there are sectors in the economy for which the marginal product of labor is not an increasing function of the level of intermediate inputs, then employment in these sectors will be negatively correlated with employment in sectors exhibiting the technological complementarities.

The point of this analysis is to demonstrate the importance of the reallocation of labor in the presence of sector specific technology shocks. This effect will generally produce negative correlations in sectoral employment levels. While a modified version of the Long-Plosser model might overcome these tendencies, it is not clear whether the specification of preferences and technology (in particular the required complementarities between labor and other inputs) is at all reasonable.

\section{Reconciliation}

There are several factors that contribute to the differences in predicted behavior across the specifications presented in Sections II and III. One important element is the imperfect competition of the Section II model. To see this, consider the equilibrium allocation from a competitive version of that model. An underemployment equilibrium may arise and is characterized by simultaneously solving the participation equation (16) and the zero profit condition of $w_{t}=p_{t}^{i}$ for all $t$ and $i$. These two curves are shown in Figure 4 which is a variation on the figure used to characterize the underemployment equilibrium in the model with imperfect competition. The competitive stationary, underemployment solution is given by the ( $w, p)$ solving these two 
equations if the resulting quantities demanded are less than $N$ in each sector. If they are not, then a full employment equilibrium results.

Since $\xi(p)<0$, the wage and price levels are $\underline{\text { higher }}$ for the imperfectly competitive economy than under perfect competition in an underemployment equilibrium. This is indicated in Figure 3 by the fact that the curve for the mark-up equation in the imperfectly competitive economy, lies below the 45 degree line. As a consequence, the set of parameter values for which an underemployment equilibrium can occur (demand at $\left(w^{*}, p^{*}\right)$ less than $N$ ) with perfect competition is a subset of that for imperfect competition.

Given that underemployment can occur with perfect competition, what is the contribution of imperfect competition to the analysis? Because prices and wages are higher due to imperfect competition, the likelihood that the economy will be in an underemployment equilibrium is higher. ${ }^{11}$ That is, if the parameters describing the economy were chosen randomly at the start of the model, than the consequence of the imperfect competition is to increase the probability that the stationary equilibrium will be in the underemployment region. As a consequence, the propagation effects of inventories on output and employment discussed above are more likely to occur.

This argument is further strengthened by noting that there are environments in which an underemployment equilibrium occurs only if some agents have market power. Hart [1982] provides such an example in which the market power of workers in the labor market supports an underemployment equilibrium in an economy for which all perfectly competitive equilibria are full employment solutions. Heller [1987] describes an economy in which workers have a zero value for leisure so that all competitive equilibria are full employment allocations. In that setting, Heller describes the possibility of an underemployment solution. In our model, setting $k=0$ would sever the linkage 
between sectors since wages would be driven to zero and workers would have no income to spend on the other sector. This problem can be circumvented either by allowing firms to spend some of their income in the other sector or by considering a contracting solution in the labor markets in which workers have some bargaining power. ${ }^{12}$

The point of the emphasis on underemployment equilibria is that the results reported in Proposition 2 only hold in the underemployment region. In the event that the economy is at a full employment solution, we obtain results very similar to the real business cycle model of Section III. That is, an increase in initial inventories in a particular sector induces a reduction in the production in that sector and a shift of resources towards the other sector. Thus the empirical observation that employment is positively correlated across sectors over the cycle (see the discussion in the next section) is produced by an economy operating in the underemployment region.

Another important part of the Section II model is the extreme nature of the disutility of work and the restriction to $\{0,1\}$ employment. This approach is used to create employment variations rather than hours. The fact that $k$ is common to all workers creates an inverted L-shaped labor supply curve and hence the two regimes noted above. ${ }^{13}$ As a consequence, the behavior of the economy across the two regimes is vastly different. If the disutility of work was continuously increasing and convex as in the Section III model, then wages and prices would vary with output and employment and this would reduce the impact on production and employment of the demand linkages across the sectors.

In fact, it is the convexity of the function characterizing the disutility of work in the Section III model that creates the negative correlations in employment since setting $g\left(n_{t}\right)=k n_{t}$ would sever the connection between the sectors. As a consequence, shocks to one sector would have no effect on 
output and employment in the other sector.

Finally, the model explored in Section III contains strong assumptions about the preferences of workers and firms. As discussed earlier, workers are "Keynesian consumers" in that their consumption of produced goods is sensitive to their income while firms only consume the non-produced good (a proxy for future consumption). This structure creates a linkage between the production in one sector and the output level of the other sector which is absent from the real business cycle model of Section III. In the latter model, consumers are effectively aggregated and their preferences over produced goods are represented by the functions $U\left(c_{t}^{i}\right)$ for $i=1,2$ and $t=1,2$.

To see the importance of the differences in tastes, suppose that in the Section II model, workers and firms had identical homothetic preferences. Then, total demand for each good would simply depend on aggregate income as if there was only a single consumer. Spending on each sector would then depend only on the revenues generated by production in the other sector and not the decomposition of these revenues into profits and wages. As a consequence, the optimal sales of the sector firm would be independent of the endowment and inventory holding of that firm and the level activity in sector 2 would be independent of these variables as we11. Thus, fluctuations in sector 1 inventories caused by variations in $e_{1}$, would not spillover to activities in sector 2 .

Overall, the models in Sections II and III capture some important forces in the effects of sectoral shocks on employment at the disaggregated level. The specification of preferences coupled with the operation of the economy in an underemployment region produces positive co-movements in the model of Section II. Sector specific shocks however may cause the substitution of workers from one sector to another as captured by the simple real business cycle of Section 
III. While these sectoral reallocation effects may be reduced by mobility costs, as in Rogerson [1987], they tend to produce negatively correlated employment fluctuations.

\section{Empirical Implications}

The models explored in Sections II and III have interesting empirical implications regarding fluctuations in output, employment and inventories both over the cycle and across sectors. In particular, the analysis suggests that models with imperfect competition may generate time series with different properties than perfectly competitive economies. To emphasize an important message, imperfectly competitive economies are, on average, predicted to exhibit less substitution across activities than their perfectly competitive counterparts.

One difficulty with confronting these models with data concerns the source of fluctuations in the economy. In most of our formal models we rely on endowment shocks to the inventoriable good as the initial source of fluctuations. Broadly speaking, these disturbances can be interpreted as resulting from sector specific shocks to tastes or technology. However, we have not formally examined whether the models of perfect and imperfect competition respond differently to aggregate demand and technology shocks. ${ }^{14}$ We conjecture though, that once inventories holdings respond to temporary shocks, our results that imperfectly competitive economies tend to exhibit positive correlations in employment and output in subsequent periods will remain.

One important implication of our work is that inventory holdings in some sectors of the economy create correlated behavior in output over time in all sectors of the economy. This is a consequence of the demand spillovers across 
sectors in a given time period. Thus one need not appeal to inventory holdings in all sectors of the economy as an explanation for observed correlated behavior economy-wide.

Another important implication of our analysis concerns the co-movement of output and employment across sectors of the economy. The analysis in Section II suggests that through the mark-ups of price over marginal cost, imperfectly competitive economies are more likely to be in an underemployment region and hence exhibit positively correlated fluctuations in output and employment. In contrast, the models explored in Section III are more likely to imply that employment fluctuations are negatively correlated across sectors. Shocks to production functions in one sector of the economy cause a reallocation of labor services from one sector to another. In their most extreme forms, the imperfectly competitive economies thus have predictions about employment fluctuations which contrast quite sharply with models of perfect competition.

To fully analyze the empirical predictions of the models in Sections II and III is beyond the scope of this paper. However, a brief examination of the data on employment across sectors is instructive to identify relevant empirical regularities. In this regard, we examine the time series and cross section behavior of employment across sectors. Table 1 presents contemporaneous correlations of employment across sectors. The data used are monthly observations on total manhours by sector for 1947:1 to 1985:12. The data used to produce the tables are log values, detrended with linear and quadratic time trends. ${ }^{15}$

Several features are worth noting from Table 1. First, virtually all of the off-diagonal terms are positive and several are quite large in magnitude. This indicates that employment exhibits substantial positive co-movements across sectors over the cycle. Further, the inventory holding sectors of the 
economy (i.e., manufacturing, and wholesale and retail trade) are quite important in this regard. That is, employment in the inventory holding sectors is highly and positively correlated with employment in the noninventory holding sectors (e.g., services).

There are, of course, several potential explanations for the observed positive co-movements across sectors. One explanation that is consistent with much of the existing macroeconomics literature is that these sectors are subject to common shocks. To shed some light on this difficult issue, Table 2 provides the correlations from the residuals from a VAR estimation using this sectoral employment data. Specifically, we estimated a VAR with the eight employment series using log values, a lag length of six and including linear and quadratic time trends in the estimation. Under some circumstances (see Sims [1980]), the residuals from this VAR estimation can be interpreted as the innovations to the respective series. Under this interpretation, examining the off diagonal elements of this correlation matrix provides evidence on whether innovations (shocks) are correlated across sectors. Further, by comparing the off diagonal elements from Table 2 to those of Table 1 , one can gain some perspective on how much of the observed positive co-movements indicated in Table 1 are due to common shocks.

A comparison of Tables 1 and 2 suggests that the observed positive comovements are not primarily due to common shocks. For example, the correlation in Table 1 between manufacturing and services is 0.63 but the corresponding correlation in Table 2 is 0.08 . This suggests that in this case common shocks account for less than one seventh of the observed positive comovement in manufacturing and service employment. Other comparisons tend to yield similar conclusions, although there are a few exceptions.

Another key issue is the nature of and the relationship between the 
persistence in the employment movements across the sectors. Table 3 presents the first order own and cross correlations across the sectors. Observe that the detrended employment series all exhibit a high and similar degree of positive serial correlation. Further, the cross lagged correlations are mostly positive and often large in magnitude. Note in particular that the correlation between lagged values of employment in the inventory holding sectors are highly correlated with contemporaneous values of employment in all other sectors. This suggests that changes in employment in the inventory holding sectors often precede changes in employment in the non-inventory holding sectors.

While these results are only suggestive, they are consistent with the predicted patterns of Section II but are not consistent with the predicted patterns of Section III. That is, there are positive co-movements in employment fluctuations across sectors which does not appear to be due to sectors experiencing common shocks. All sectors exhibit a high and similar degree of positive serial correlation. The inventory holding sectors seem to play a fundamental role in this regard as changes in employment in the inventory holding sectors precede and contemporaneously move with changes in employment in the non-inventory sectors.

\section{Conclusions}

The twin observations of serially correlated output movements and positive co-movements in output across sectors of a multi-sector economy are two important "stylized facts" that guide macroeconomic researchers. The important paper by Long-Plosser [1983] provides one possible explanation for these features based on the normality of consumption goods in preferences and a technology which allows for the production of commodities by commodities. 
As a consequence, the linkage highlighted in their paper are intersectoral demands for intermediate goods.

This paper investigates an alternative approach which stresses linkages across sectors from the demand for consumption goods and the presence of imperfect competition. The market power of sellers produces an environment in which an underemployment equilibrium is likely to arise. In that case, shocks to one sector of the economy spillover to others and generate positively correlated output and employment movements. The linkage across time explored in this paper is the holding of inventories by a subset of agents in the economy. Because of the demand linkages across sectors, the holding of inventories by some firms is enough to produce correlated output movements in all sectors.

This model is then contrasted with a real business cycle model without the factor demand flows stressed by Long-Plosser. For that setting, positively correlated employment fluctuations across sectors is not likely to occur. Instead, shocks to one sector will generally generate a substitution of factors to one sector from the others. Hence, the predictions of the two models with regards to employment fluctuations are quite different.

Drawing on these implications, we investigated detrended data on employment fluctuations. Our primary finding was positive co-movement in sectoral employment over the cycle which does not appear to be due simply to sectors experiencing common shocks. We interpret these findings as supportive of both the model of imperfect competition explored in Section II of the paper and a version of the Long-Plosser model in which technological complementarities dominate. These results do appear to be contrary to the predictions of many simple real business cycle models in which sector specific shocks induce the sectoral reallocation of labor. 
Our analysis leaves open a number of interesting and important questions. First, we have only analyzed a two period model and have interpreted the differences between worker and shareholder preferences as a difference in savings behavior. One important extension of our model would therefore be to derive these differences more explicitly. One avenue would be to allow the firms as an institution to be infinitely lived. Shareholders could live for finite periods of time and be able to operate in capital markets while workers would live for a single period. In this setting, the non-produced good could act as a store of value for shareholders, i.e. it could simply be money so that the demand for this good was a means of obtaining future consumption. Owing to their single period of life, which is a proxy for exclusion from capital markets, workers would have no demand for this good.

Second, we have not really incorporated into our analysis any intertemporal strategic interactions. While these are apparently not necessary to generate the time series and cross-sector variations of interest in this paper, these interactions by themselves might be worthy of attention.

Third, firms hold inventories in our model as a store of value. While this is analytically convenient, this is unlikely to be the only (key) reason for inventory holdings. In future work, we plan to integrate into our analysis a more reasonable rationale for inventory holdings along the lines of production bunching as discussed by Ramey [1987]. ${ }^{16}$ Nonetheless, we conjecture that the dynamic effects of inventories will remain even in a setting with a richer explanation for inventory holdings.

Finally, a full comparison of this approach with that of Long-Plosser to understanding co-movements across sectors seems warranted and would best be achieved by the construction of a model which incorporated in it markets for both final goods and intermediate products. This would allow us to evaluate 
the role of imperfect competition at each stage of the production process and to, perhaps, explore the causal linkages between sectors linked together by both factor and final goods demands. 


\section{Appendix: Proof of Proposition 1}

First, we must demonstrate that if $e_{1}=0$ and $\mathbb{M}^{i}=\mathbb{M}$, then (4) and (16) will characterize the prices and wages in an underemployment equilibrium. Because of the homothetic preferences, the price of each good in each period will be the same. Hence the wage rates must be the same each period for (16) to hold. Since marginal revenue is assumed to be a monotonically increasing function of price, prices will be the same each period.

We must verify that $\left(w^{*}, p^{*}\right)$ solving (4) and (16) exist. Figure 3 is a graphical representation of (4) and (16). Marginal revenue, $d[p(1+\xi(p)] / d p$, is assumed to be strictly positive so that the graph of (4) has a strictly positive slope for all p. As $\mathrm{p} \rightarrow 0$, so must $w$. Otherwise, the worker would obtain infinite utility from positive $w$ at $p=0$. The slope of (16) is the workers level of spending on the produced good which goes to infinity as $\mathrm{p} \rightarrow 0$ and approaches 0 as $\mathrm{p} \rightarrow \infty$. These two limit properties plus the quasi-convexity of the indirect utility function implies that there will be at least one crossing in Figure 3.

To show that the left side of (17) expresses output in each period for each sector, note that (13) is satisfied at $I_{1}=0$ so that the sectors are identical over time. Hence the solution will be symmetric and if (17) is satisfied, the quantities demanded can be produced so that an underemployment equilibrium will occur. Clearly, this condition is more likely to be satisfied if $\mathrm{N}$ is large and $\bar{M}$ small. 


\section{References}

Abraham, K. and L. Katz, "Cyclical Unemployment: Sectoral Shifts or Aggregate Disturbances?", Journal of Political Economy, 94 (1986), 507-522.

Arvan, L. "Some Examples of Dynamic Cournot Duopoly with Inventory," Rand Journal of Economics, 16 (1985), 569-586.

Blinder, A. "Can the Production Smoothing Model of Inventory Behavior be Saved?" Quarterly Journal of Economics, 101 (1986), 431-453.

and S. Fischer, "Inventories, Rational Expectations and the

Business Cycle," Journal of Monetary Economics, 8 (1981), 277-304.

Cooper, R. "Optimal Labor Contracts, Imperfect Competition and Underemployment Equilibria: A Framework for Analysis," NBER Working Paper \#2060, 1986.

Multiple Equilibria," NBER Working Paper \#2388, 1987.

and A. John. "Coordinating Coordination Failures in Keynesian Models," Cowles Foundation Working Paper \#745R, revised September 1987, forthcoming Quarterly Journal of Economics.

Diamond, P. "Aggregate Demand Management in Search Equilibrium," Journal of Political Economy, 90 (1982), 881-94.

and D. Fudenberg, "Rational Expectations Business Cycles in Search Equilibrium," mimeo, 1986.

Dynarski, M. and S. Sheffrin, "Consumption and Unemployment," Quarterly Journal of Economics, 102 (1987), 411-428.

Eichenbaum, M. "Rational Expectations and the Smoothing Properties of Inventories of Finished Goods," Journal of Monetary Economics 14 (1984), $71-96$.

Hall, R. "A Non-competitive, Equilibrium Model of Fluctuations," Stanford University, mimeo, 1987a.

. "The Volatility of Employment with Fixed Costs of Going to Work," Stanford University, mimeo, $1987 \mathrm{~b}$.

Hansen, G. "Indivisible Labor and the Business Cycle," Journal of Monetary Economics, 16 (1985), 309-327.

Hart, 0. "A Model of Imperfect Competition with Keynesian Features, " Quarterly Journal of Economics, 97 (1982), 109-38.

Heller, W. "Coordination Failure Under Complete Markets with Applications to Effective Demand," in Equilibrium Analysis, Essays in Honor of Kenneth $J$. Arrow, Volume II, edited by Walter Heller, Ross Starr and David Starrett, Cambridge, Cambridge University Press, 1986. 
. "Coordination Failure with Temporary Equilibria," Notes presented at NBER Summer Institute, July 1987.

Howitt, P. "Transactions Costs in the Theory of Unemployment," American Economic Review, 75 (1985), 88-101.

Kiyotaki, N. "Implications of Multiple Expectational Equilibria Under Monopolistic Competition," Harvard University, mimeo, 1985.

Kydland, F. and E. Prescott. "Time to Build and Aggregate Fluctuations," Econometrica, 50 (1982), $1345-70$.

Lilien, D. "Sectoral Shifts and Cyclical Unemployment," Journal of Political Economy, 80 (1982), 777-793.

Long, J. and C. Plosser. "Real Business Cycles," Journal of Political Economy, 91 (1983), 39-69.

Lucas, R. "Expectations and the Neutrality of Money," Journal of Economic Theory, 4 (1972), 103-24.

. "An Equilibrium Model of the Business Cycle," Journal of Political Economy, 83 (1975), 1113-1144.

"Understanding Business Cycles," in Stabilization of the Domestic and International Economy, ed. by $\mathrm{K}$. Brunner and Allan H. Meltzer, Carnegie-Rochester Conference Series on Public Policy,5. Amsterdam:NorthHolland, 1977.

Ramey, V. "Two Studies of Inventory Investment: Inventories as Factors of Production and Nonconvex Costs in the Production Smoothing Model," PhD. dissertation, Stanford University, 1987.

Rogerson, R. "An Equilibrium Model of Sectoral Reallocation," Journal of Political Economy, 95 (1987), 797-809.

Rotemberg, J. and G. Saloner, "The Cyclical Behavior of Inventories," mimeo, 1987.

Sims, C. "Macroeconomics and Reality," Econometrica, 48 (1980), 1-48.

Weitzman, M. "The Simple Macroeconomics of Profit Sharing," American Economic Review, 75 (1985), 937-53.

Zarnowitz, V. "Recent Work on Business Cycles in Historical Perspective," Journal of Economic Literature, 23 (1985), 523-580.

Zeldes, S. "Consumption and Liquidity Constraints: An Empirical Investigation," Working Paper \#24-85, Wharton School, University of Pennsylvania, 1985. 
TABLE 1

Contemporaneous Correlations of Logs of Employment ${ }^{1}$

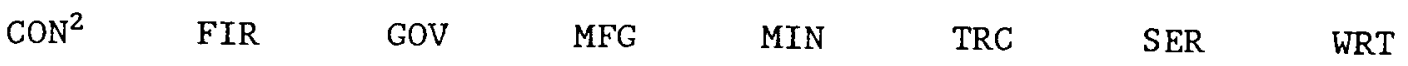

CON $\quad 1.00$

FIR $\quad 0.62 \quad 1.00$

GOV $\quad 0.19 \quad-0.04 \quad 1.00$

$\begin{array}{lllll}\text { MFG } & 0.61 & 0.29 & 0.54 & 1.00\end{array}$

$\begin{array}{llllll}\text { MIN } & 0.23 & 0.31 & -0.13 & 0.14 & 1.00\end{array}$

$\begin{array}{lllllll}\text { TRC } & 0.71 & 0.44 & 0.56 & 0.76 & 0.13 & 1.00\end{array}$

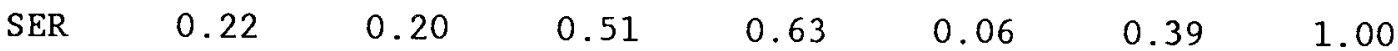

$\begin{array}{lllllllll}\text { WRT } & 0.60 & 0.51 & 0.59 & 0.79 & 0.28 & 0.76 & 0.58 & 1.00\end{array}$

${ }^{1}$ Detrended--see text for explanation.

${ }^{2}$ Abbreviations: CON - Construction; FIR - Finance, Insurance, Real Estate; GOV - Government; MFG - Manufacturing; MIN - Mining; TRC - Transportation and Public Utilities; SER - Services; WRT - Wholesale and Retail Trade. 
TABLE 2

Contemporaneous Correlations of Employment Innovations ${ }^{1}$

\begin{tabular}{|c|c|c|c|c|c|c|c|c|}
\hline & $\tilde{\mathrm{CON}}$ & $\tilde{F I R}$ & $\tilde{\text { GOV }}$ & $\tilde{\mathrm{MFG}}$ & $\tilde{\operatorname{MIN}}$ & $\tilde{\text { TRC }}$ & $\tilde{\text { SER }}$ & WRT \\
\hline$\tilde{\mathrm{CON}}$ & 1.00 & .06 & .30 & .30 & .13 & .09 & .12 & .28 \\
\hline$\tilde{F I R}$ & & $1.00:$ & .05 & .06 & -.05 & .00 & .10 & .15 \\
\hline$\tilde{\mathrm{GOV}}$ & & & 1.00 & .17 & .10 & .10 & -.01 & .06 \\
\hline$\tilde{M F G}$ & & & & 1.00 & .25 & .27 & .08 & .31 \\
\hline$\tilde{\operatorname{MIN}}$ & & & & & 1.00 & .26 & .04 & .11 \\
\hline TRC & & & & & & 1.00 & -.05 & .11 \\
\hline$\tilde{S E R}$ & & & & & & & 1.00 & .16 \\
\hline$\tilde{\text { WRT }}$ & & & & & & & & 1.00 \\
\hline
\end{tabular}

${ }^{1}$ See text for explanation. 
TABLE 3

Correlation Matrix of the Logs of Employment at $\operatorname{Lag} 1^{1}$

$\begin{array}{lllllllll} & \text { CON } & \text { FIR } & \text { GOV } & \text { MFG } & \text { MIN } & \text { TRC } & \text { SER } & \text { WRT } \\ \text { LCON } & 0.90 & 0.63 & 0.17 & 0.60 & 0.23 & 0.70 & 0.23 & 0.61 \\ \text { LFIR } & 0.61 & 0.95 & -0.07 & 0.27 & 0.32 & 0.41 & 0.20 & 0.50 \\ \text { LGOV } & 0.16 & -0.04 & 0.91 & 0.53 & -0.13 & 0.56 & 0.51 & 0.59 \\ \text { LMFG } & 0.60 & 0.32 & 0.54 & 0.99 & 0.15 & 0.77 & 0.64 & 0.82 \\ \text { LMIN } & 0.21 & 0.30 & -0.16 & 0.12 & 0.86 & 0.11 & 0.06 & 0.26 \\ \text { LTRC } & 0.70 & 0.46 & 0.56 & 0.75 & 0.15 & 0.98 & 0.40 & 0.78 \\ \text { LSER } & 0.19 & 0.21 & 0.51 & 0.60 & 0.06 & 0.37 & 0.89 & 0.59 \\ \text { LWRT } & 0.58 & 0.52 & 0.58 & 0.75 & 0.27 & 0.75 & 0.58 & 0.94\end{array}$

${ }^{1}$ Detrended--see text for explanation.

${ }^{2}$ The prefix $L$ indicates the lagged series. 


\section{Footnotes}

1. Long-Plosser present simulation of output fluctuations in a multi-sector setting using their model of factor demand linkages but do not discuss employment variations. We provide empirical evidence in Section $V$ of this paper on employment fluctuations.

2. There is a literature on sectoral flows of workers in the presence of sector specific shocks. See, Lilien [1982] and Abraham-Katz [1986] for a discussion of these flows and their relation to aggregate economic activity. Rogerson [1987] discusses sectoral flows in a two-period model with sector specific shocks. His model implies negative correlations in employment levels as workers move from one sector to another.

3. Strictly speaking, imperfect competition is not necessary for the effects discussed here to occur. As discussed in Section IV, the market power of firms increases the probability that the economy will be in an underemployment region.

4. This assumption of competitive labor markets is reasonable if the economy was composed of a large number of monopolized sectors. In our two sector model, this assumption is a bit strong. Cooper [1986] analyzes an alternative way of characterizing labor market equilibrium through a contracting process in which the variations in the market power of workers and firms are easily analyzed.

5. Additional properties of the demand curves are discussed in Hart [1982].

6. Zeldes [1985] provides empirical evidence that liquidity constraints are important for explaining consumption behavior. Dynarski and Sheffrin [1987] argue that the consumption behavior is dependent upon an agent's employment status which is consistent with the proposition that unemployed workers are liquidity constrained.

7. We assume that marginal revenue is a strictly increasing function of $p$.

8. If there are multiple equilibria, they will generically be locally unique so that in response to variations in $e_{1}$, the equilibrium is assumed to vary in the neighborhood of the chosen stationary equilibrium. See Cooper [1987] for a discussion of selection for economies of this type.

9. Figures 1 and 2 should be be viewed as representing quantity interactions across sectors at the equilibrium prices $\left(w^{*}, p^{*}\right)$ characterized in Proposition 1. The economy will remain in an underemployment equilibrium if it starts there for a sufficiently small change in $e_{1}$.

10. Even if $U()$ is so concave that income effects dominate, as long as $g()$ is strictly convex, productivity shocks still generate substitution of employment across sectors.

11. Similar arguments appear in Cooper [1986] and Hall [1987a].

12. This approach is described in Cooper [1986]. 
13. One objection to this approach is that this specification appears to contradict evidence that the labor supply of full-time workers is relatively inelastic. Our model is primarily concerned with variations of employment on the extensive margin for which the evidence is much less conclusive. See Hansen [1985] and Hall [1987a,1987b] for discussions of this point.

14. The discussion at the end of Section III provides a preliminary extension of Proposition 3 to technology shocks. See Cooper [1986] for a discussion of demand and supply disturbances in a model of imperfect competition.

15. We also considered alternative detrending methods, such as log first differences. Results on correlations in employment changes across sectors were similar to those reported in Tables 1 and 2. However, this approach did seem to over difference the data and hence generate some negative serial correlation.

16. One possibility we will explore is a production bunching model in which firms incur a fixed cost of "starting up the piant" and a low marginal cost up to capacity. This setting is described by Ramey [1987] as capturing the technology of a number of industries and implies that production is more volatile as sales as suggested by recent empirical evidence (see, for example, Blinder [1986]). 